\title{
Traditions of National World Formation in the Poetics of Yakut and Korean Prose by Ariadna Borisova "The Land of the Udagans" and Lee Hyun Soo "New Tales of Gisaeng"
}

\author{
Svetlana Barashkova, Svetlana Zhelobtsova \\ North-Eastern Federal University named after M.K. Ammosov, 677000, 58 Belinsky str., Yakutsk (Republic of Sakha), Russian Federation
}

\begin{abstract}
The article compares peculiarities of poetics of the olonkho novel "The Land of the Udagans" by the Yakut writer Ariadna Borisova and the legendary novel by the South Korean writer Lee Hyun Soo "New Tales of Gisaeng". The study of traditions of the national world image based on the materials from different ethnic cultures from the gender perspective revealed the artistic individuality of authors representing the world of the Arctic and Southeast Asia. The comparison of the works by Yakut and Korean writers revealed the life-giving role of women in society and its crisis. The heroines represent a typological model of female fate in different images. Women are carriers of the traditional cultural and moral values based on the family value. The text-forming role of artistic details is significant. It makes the text real, reducing the distance between the author and the reader. Describing the real world of the heroines, their way of life, the space of their houses, the writers strive to outline the female everyday worldview and the national picture of the world
\end{abstract}

\section{Introduction}

The comparison of the literary material actualizes the literary study of poetics, reveals the gender nature of the female world image. The study of the Yakut and Korean novels makes it possible to reveal general and particular locations of cultural traditions, reveal the role of women, psychologism of their characters. Creativity of women, having gone through a thorny path to recognition, overcoming male criticism, has been marked by many literary awards. This is evidenced by a significant increase in the number of Nobelite writers in the 21st century. The International Literature Prize was awarded to Elfrida Jelinek (2004), Englishwoman Doris Lessing (2007), Gerta Muller (2009), Alice Munro (2013), Svetlana Aleksievich (2015), Olga Tokarchuk (2018) and Louise Gluck (2020). In the $20^{\text {th }}$ century, out of 100 laureates, only 8 were women.

The problem analysis of literary works is aimed at identifying components of the national world image, structurally realized in the figurative system, the description of everyday life, clothing, religious rituals and cosmogonic ideas.

Author's observations characterize the genre searches of the writers who updated the olonkho canons and legends: the olonkho novel (A. Borisova) and the legendary novel (Lee Hyun Soo). The semantic space of works is based on the original archetype of the peoples of the Arctic and Southeast Asia. The literary concept of the article highlights the gender system of the worldview vision, being and time.

\section{Materials and Methods}

The world image, is an important fragment of the picture of the world, which became the subject of philosophical research in the 20th century [1]. This problem is fruitfully and diversely resolved in linguistic research [2-3]. When analyzing multi-national literature, the process of formation of an ethnic world image based on peculiar cultural traditions (life, religion, folklore, language) is observed. The content of narration presented in the author's interpretation reveals the functional role of details, which is important for the holistic perception of the spiritual life of people. Author's observations of the dynamics of the gender nature of female prose substantiate the relevance of reflections of the literary critic Esin. [4] on the conventionality of dividing parts into external and internal. After all, the female world consists of an interweaving of the real and the sensual, pragmatic and illusory, psychologically experienced by the heroine and transmitted by her to the world.

The choice of the works is justified by the artistic level of the texts, the reader's demand for the writers' prose and the intention of Ariadna Borisova to present the original mythology of the Sakha people, and that of Lee Hyun Soo to preserve traditional Korean values . Literature is a part of culture. The article develops the strategy of gender literary studies, who origins were developed in the middle of the 20th century, as a continuation of the actualization of the role of gender in the system of humanities from sociology and linguistics to philosophy and political science [5]. Research in this area continues to be replenished with new interdisciplinary works. For the article, judgments of the literary critic Pushkar are conceptually important: "the interpretation of works from a gender perspective should be literary rather than sociological; it should be based on an analysis of social and psychological conditions of the narrator and his heroes" [6]. The work by Zherebkina, director of the center for gender studies and editor of the journal "Gender Studies" [7] is also important. In Russian 
literary criticism, the research by Rovenskaya [8] is crucial. It restores the stages of development of female literature in Russia from realism to postmodernism, their cultural and linguistic codes and feminist criticism. For the interpretation of a literary text at the turn of the 20th and 21st centuries, marked by the globalization tends and the search for universal values, interdisciplinary works that go beyond the framework of one national literature are significant [9]. The work uses the historical-comparative method that reveals the evolution of female literature in its semantic locations, when the ethnic component becomes a cultural marker that inscribes a symbolic character into the sociosphere.

\section{Results and Discussion}

The Yakut writer Ariadna Borisova, laureate of the Great Literary Prize of Russia, nominee for the "Russian Booker2007" award is associated with the original national material. In 2005, UNESCO recognized olonkho as an intangible masterpiece of oral folk art. The novel begins with the prologue, which indicates a date (October 29, 2001, at 15 minutes to nine in the evening), a place (the hospital emergency room) and characters (an intern doctor, an elderly nurse, a female trainee and a woman in labor). The birth of a child is accompanied by a struggle with dark forces that are trying to destroy the child with God's mark. "The storm beat frantically against the walls of the old building ... as if someone's sharp claws were scratching them outside. That wild and inexplicable, that was mad from the outside, behaved like a revived fantastic creature and rushed inward..." [10]. In this dramatic situation, an involuntary appeal to the Lord with prayer resolves the conflict between Good and Evil: the child was born, and the storm ended.

The compositional link between the present and the mythological time is the author's reminiscence of the legend about the creation of the Middle Earth and the people of the Sakha tribe. The writer reconstructs the canonical form of olonkho, in which the improviser begins the narration exclaiming "Domm!". The genre transformation gives the word the magical power of the olonkhosut-narrator, establishing an intimate connection with the reader. The novel "The Land of Udaganoks" is a recreation of the Yakut national traditions, rituals, mystical legends of folklore origin. The vocabulary of the novel contains untranslated Yakut words denoting the names of gods, spirits, months, utensils, clothes, etc. Borisova supplements the text with an "explanatory dictionary", which reveals the meaning of Yakut words. For example, Aiyy-Sita is the patron of women and families; Jogur means gift, talent; Yor means the evil spirit of the dead; Ytyk is a whisk for whipping milk dishes. Month names indicate the natural phenomena: March is the month of birth of calves, November is the month of frozen lakes. These words and expressions, presented in transcribed form are necessary to create a specific flavor of the time and national picture.

The original source of the book is Olonkho, a Yakut heroic epic. It consists of legends, usually called by names of heroes ("Nyurgun Bootur", "Meldew the Strong", etc.). In historical and ethnographic terms, this mythological epic is a legend about the exploits of heroes. Reading the exposition and observing the development of the plot reveal the writer's plan, according to which women - wives of hunters, blacksmiths and shamans - are the fundamental principles of Life. Legends become a logical reminiscence in the poetics, explaining the role of three Mistresses of the Circle keepers of 9 Udagan commandments. These are respected women who are engaged in the sacred pottery craft: "The magic battle of the Hostess's beater is thunderous in the echoing vaults of the Lower World" [10]. In the system of symbolic metaphors, there are female activities, utensils, clothing, and household items: Kes is a pot for cooking meat, it is also a measure of space. A knife for a boy and scissors for a girl were used to cut the umbilical cord. The skill of describing everyday life is manifested in a detailed description of the clothes that Uranus's wife sews for her newborn son: the reindeer doha is trimmed with a spotted lynx edge, the beaver inserts are decorated with iron piercings and copper plaques, the belt strap is decorated with cast plaques of white and blackened silver, the boots are lined with leather from the nape of an elk.

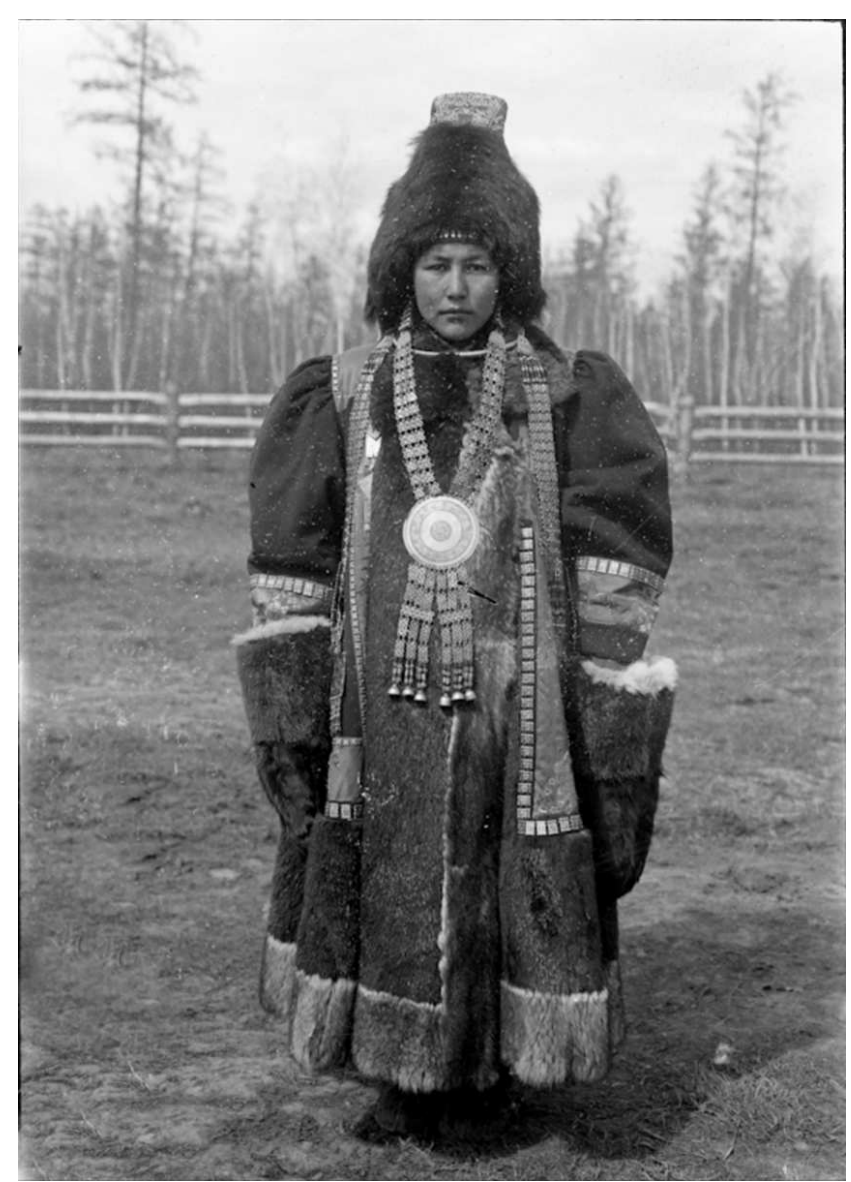

Fig. 1. Yakut Udaganka Anna Pavlova, the beginning of the 20th century.

The chronotope of the epic time and mythological space of the three worlds is compositionally reduced to the Middle World. The people cherish the ritual of feeding the spirit of fire, the forest, the sacred tree. The climax of coincides with energy of the epic, and the birth of a child is interpreted as the birth of the Earth. An analysis of the fragment about the burial of the Udaganka is presented as a process of reincarnation of her body and spirit. Having prepared an air 
grave, dressed in a white outfit with bells, picking up an eight-rayed bowl, wrapped in birch bark, she "lay inside a tree womb, like an unborn child, and the daylight darkened in her outdated eyes" [10]. The author uses the artistic technique of the ring composition, according to which the heroine, the wife of the warrior-hunter Naryan, comes to the rock of Udaganka to give birth, fleeing from evil spirits.

Psychological research of female features reveals female gift - Dzhugur - an ability to kindle a fire, to heal with herbs creative abilities. But their main mission is to give and keep life. The ending is marked with a symbolic image: "The drop lived and breathed. Like all living things, she wanted a continuation for herself. And so the drop swelled up like a cup-womb, in which the mother's essence was born. Now the mother's essence is everywhere - in the sky, water and even in the sun" [10]. The leitmotif of the novel is protection of the child who is the heir to the Family. Thus, Ariadna Borisova introduces gender accents in the interpretation of the epic text, creatively weaving it into the modern narrative.

The Yakut author is close to the South Korean writer Lee Hyun Soo in terms of the style of using with ethnomaterials, the ability to see the Being of a woman. She made her debut in 1991 in the Chuncheon Daily with her story "Misfortune Started With Fingers." In 1996 she received her first Literary Award. New Tales of Gisaeng were published in 2005. Lee Hyun Soo explains the concept of the work with strong impressions from interviews with gisaeng and visits to the graves of Buyeongak gisaeng. When creating the figurative system, she relies on the real stories of these women who fell into kibans. Ming is one of the main characters. The dramatic plot reveals the childhood of a girl, who was not needed because her father wanted a son. The little singer was given away by her mother at the age of 9 , thus trying to interrupt the fate of widowhood in their family.

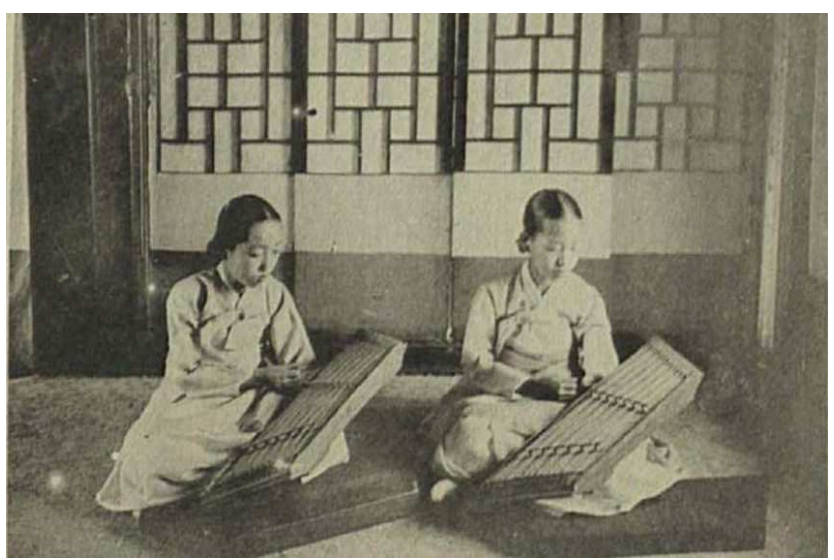

Fig. 2. Korean gisaeng

An analysis of the genre nature of the text explains its definition as a legend that transforms the folklore layer. Therefore, in the plot counterpoints, the canonical elements of the tale are manifested: the beginning, three sisters, distant lands, twelve mountains and rivers, a dream of a happy future. The semantic content of the title refers to the well-known phenomenon of Korean culture, which designates the ancient female profession. Gisaengs who studied dance, music, songs, poetry, and etiquette, contributed to the preservation of folk traditions. Being educated, they left behind a spiritual legacy. However, over time, the perception of gisaeng as an intellectual interlocutor has changed. In the 20th century, kibans were closed everywhere, turning into ordinary brothels, losing their original purpose. Lee Hyun Soo focuses on the story of Kiban Buyongak, which cherishes the atmosphere of the past. The kiban becomes a home, where the Korean family traditions are observed: holidays, rituals (weddings, funerals); the owner of the kiban, cook Tabakne, bears the burden of the head of the family. For Lee Hyun Soo, the family is significant, valuable for a Korean woman.

Among the artistic means used to reproduce the polysyllabic material is retrospection. An important role belongs to old recipes and table setting rules. The writer takes into account the cult of food, which has become a mental trait of Koreans. Tabakne, who knows the intricacies of cuisine and transfers this skill to her young assistant, says: "This recipe has come down to us from antiquity, remember it once and for all. Unlike the food of ordinary people, kiban food should be better processed with sauce and have a piquant taste. In other words, it should be slightly salty or have a sweet and sour taste" [11]. It is no coincidence that Buyeongak is bypassed by thieves and robbers, everyone knew that Tabakne fights back and is ready to sacrifice any part of her body to preserve her hands and tongue which are important tools for cooking. The taste of food is associated with memories of home, childhood, mother. The importance of the Hearth - Kitchen - Food Mother is emphasized.

Tabakne, a seemingly stern, grumbling, elderly woman, becomes a through character, who plays different roles. In some episodes, she is a business owner of the kiban with her principles and material interests; in others, she is a cook who takes care of the girls. The story of a 12-year-old gisaeng is indicative. Tabakne snatched her from the lustful hands of a guest and became a faithful friend, helping her. The girl became a talented singer and tool a special place in kiban. The gisaeng kept Tabakne until she became a famous cook and owner of Buyongak.

The author creates a psychologically complex and multifaceted image of the keeper of the past, who knows how to describe the nationality of the heroine. "In summer, she wore a white ramie mosijoxam and gray hemp mompe trousers, and in winter, she wore a Korean quilted nuvijoxam shirt and loose black mompe trousers. Only when she had to enter the room with visitors did she dress up festively: she put on dark green silk mompe." [11]. The description of a gisaeng wedding dress is plotted and psychologically motivated: "The dress was embroidered with hieroglyphs asking for the grace of the wave, tigers, peony, lotus, inscriptions" [11]. In the typological series of the characters, the image of the dancer Ming stands out. She grew up among the sisters who sent the younger one to an expensive national dance school. However, following the Confucian principle of duty to elders, the girl voluntarily leaves for kiban so as not to ruin the sisters. Really justified is her consent to undergo the hwachomori ceremony, which means that after this ritual Ming will be officially recognized in all kibans of the country as a real gisaeng. From that moment on, she got up on the road from which it was no longer possible to turn off. The drama of the 
decorative wedding is emphasized by a bride dance "Salphuri" (Autumn leaf fall) in front of the husband. An important technique of characterization is the disclosure of the semantic name of the dance. Ming's movements are filled with sadness. The choice of the season emphasizes the extinction of the life cycle. Gisaengs are girls with faith in love, family happiness, forced to remain at the bottom of life, like fallen leaves.

Poetics of the novel is characterized by an appeal to the aesthetics of folk songs; for example, the o Song of Youth (Chongchunga) becomes a symbol of the state of mind of gisaengs. It is no coincidence that the "last" kiban singer knows the traditional meanings and tonality of songs: "We must sing so that listeners feel inescapable sadness, longing, pain... Kemeungjo's tone is woeful, pleading. It is also called "sansong", a depressingly rising tone [11]. The expressive style, emotionality of the author's word permeate the colorful monologue of the singer, describing more than 30 tones of the folk song ("bread, yellowish, dry, hardened, fresh, internal, external, enveloping, prickly, unraveling, squeezing, pushing, bell-shaped, burning, digging, scattering, tearing off, dry, weaving, intermittent, insinuating, exploding, military, extended, wet, carrying, lazy, sleeping") [11]. Lee Hyun Soo deliberately chooses multiple connotations of the song's sound, while retaining the original folk spirit.

The repeated use of cultural and everyday details determined the need to accompany the translation of the novel with a dictionary. The reader learns that dalgaltsim is the name of a dish made from steamed, beaten eggs, and mompe is the name of wide trousers that women wore while working, or Salphuri is a traditional dance to drive out unclean spirits. These dictionaries allow readers to comprehend the psychological implications of the narrative.

The singer, the dancer and the cook are the backbone of traditional kibans. The artistic series of the characters is symbolically complemented by the metaphorical image of a wooden pillar supporting the roof. In addition, in the system of expressive means, the floor made of sturdy boards, which have darkened with time. Tabakne refuses to sell it. It seemed to her that if you varnish it, the soul of the kiban hidden in the natural texture of the tree disappears. The floor witnessed many dramas, absorbed gisaeng tears, remembered their light steps, absorbed hair smells. The laconic description of details deepens and enriches the content of the legendary novel. The detail reveals the sensual spectrum of characters' features, evolving from childish naivety to adult cynicism. Lee Hyun Soo talentedly represents the author's thoughts through iconic symbols that have become firmly established in the world image of Koreans.

\section{Conclusion}

The regularity of interaction of the traditional and the new in the world image of ethnocultures is obvious in the modern literature. Reading female prose from a gender perspective allows us to highlight features of the psychological and personal world of heroines. The comparison of the works by the Yakut and Korean writers emphasizes the life-giving role of women in society. The heroines represent a typological model of female fate in different images, women are carriers of the traditional cultural and moral values of the peoples. The authors consider the material world in a multilayered and gender-oriented way, going beyond the private to the general. Describing the life of the heroines, their way of life, the space of their houses, the writers strive to designate the everyday worldview as the key to discovering the traditional way of life of the ethnos.

The analysis of the literary works allowed us to draw the following conclusions:

1. The creative concept of the works determines the choice of genre aesthetics: Ariadna Borisova introduces the Sakha people's epic in the form of the olonkho novel "The Land of the Udaganok", and Lee Hyun Soo uses a legend that allows her to preserve the disappearing part of the national culture.

2. The function of the writers' creative searches is to describe the semantic space of everyday life, which reveals the main female abilities as procreation, healing, and preservation of the Hearth. Detailed reality is filled with spiritual content, raising everyday life to Being.

3. Observations on the poetics of the texts indicate the creativity of female writers when working with folklore sources. The author's interpretation of the epic images and motifs in the olonkho novel by A. Borisova and the retrospection of folk songs, dances, food and clothing of Koreans by Lee Hyun Soo create a world image of each nation.

\section{References}

1. G.G. Starikova, The variety of pictures of the world and features of the linguistic picture of the world, retrieved from: http://naukam.triada.in.ua/index.php/konferentsiji/56dvadtsyat-shosta-vseukrajinska-praktichnopiznavalna-internet-konferentsiya/672mnogoobrazie-kartin-mira-i-spetsificheskieosobennosti-yazykovoj-kartiny-mira

2. O.P. Kanalash, National picture of the world as a component of linguistic research, LINGUA MOBILIS, 6(39), 70-73 (2012)

3. A.Yu. Sadofieva, Cultural and everyday detail in a literary text. The Bulletin of Moscow University. Series 19. Linguistics and Cross-Cultural Communication, 2, 129-136 (2008)

4. A.B. Esin, The principles and techniques of the analysis of a literary work (Flinta, Moscow, 2000)

5. S.N. Barashkova, S.F. Zhelobtsova, The artistic world of women's prose (Yakutsk: North-Eastern Federal University, 2009)

6. G.A. Pushkar, Gender originality of Russian women's prose at the turn of the 20th and 21st centuries, Science. Innovations. Technologies, 50, 242-248 (2007)

7. I.A. Zherebkina, Introduction to gender studies (Kharkiv: Kharkiv Center for Gender Studies; SaintPetersburg: Aleteya, 2001) 
8. T.A. Rovenskaya, Women's prose of the late 1980s and early 1990s (issues, mentality, identification), phD thesis (Moscow, 2001)

9. O. V. Sizykh, S.N. Barashkova, S.F. Zhelobtsova, Educational and gender issues and the mythopoetic context of the contemporary Russian and Korean novel: L Ulitskaya "Medea and her children" and L. Hyeon-Su "New Tales of Gisaeng", International Journal of Mechanical Engineering \& Technology (IJMET), 9(9), 1202-1211 (2018)

10. A. V. Borisova, Land of the Udagans. Omen of the storm (Yakutsk: Publishing house Bichik, 2008)

11. L. Hyun Soo, The Legend of the New Gisaeng (Hyperion, Saint-Petersburg, 2013) 